\title{
Skills of Improving the Competitive Level of Tennis
}

\author{
Sheng Luo \\ Aba Teachers University, Aba, 623002
}

Keywords: tennis competition, skill, countermeasure, research

\begin{abstract}
In recent years, with the steady improvement of China's economic level and the gradual increase of people's spiritual and cultural needs, sports fitness activities are generally more and more popular among people. Not only the slogan of national sport is known by everyone, but also the concept of national sport is more deeply rooted in people' minds, thus promoting the vigorous development of tennis. More and more people join tennis industry, greatly promoting the development of tennis as a competitive sport. But comparatively speaking, the development and popularization level of competitive tennis education in our country are still far behind those countries with mature tennis development. Therefore, in order to fundamentally solve this problem, it is vital to first of all analyze the current development situation of tennis in China and put forward specific rectification measures and solutions in view of existing problems in the development of tennis education in China. Therefore, in-depth analysis of current situation and problems affecting the development of competitive tennis in China is of great significance for guiding the long-term development of tennis in China.
\end{abstract}

\section{Training Situation of Tennis Players in China}

Most of the major tennis players in China come from sports schools at all levels, tennis related clubs and characteristic tennis learning schools. There are some differences in the specialization of tennis teaching activities among these three, as well as in the difficulty and intensity of training and the degree of specialization of training system. This shows that the grass-root organizational training of tennis education in China lacks scientificity and specialization. In terms of teaching staff, China still thirsts for professional tennis teaching staff, advanced tennis technology and experience, and systematic tennis tactics construction system. While these factors are the fatal shortcomings of our country in developing tennis education.

\section{Development of Competitive Tennis in China}

The public's understanding and admiration of sports events is an important factor affecting the long-term development of the sports. Therefore, in the propaganda of tennis sports, we should firstly expand publicity, enhance public's enthusiasm for tennis sports, attract more people to learn, and enhance their psychological identity. Secondly, we are required to cooperate with relevant media to enhance the influence and dissemination of tennis sports. Compared with developed countries, the popularity of tennis in China is relatively low, mainly because the introduction of tennis into China is so late that people have less and superficial awareness of the sport without enough propaganda. Tennis is regarded as an elegant sport in foreign countries. Due to the limitation of economic level and the obvious social stratification, only a small number of people have the conditions to accept formal learning, so the development of this sport has lagged behind. But now, China's economy is catching up with other developed countries with rapid development, so people are increasingly promoting and supporting sports. Nowadays, people have regarded tennis as a fashionable social activity, and the public awareness has been generally improved.

The development of tennis is not only determined by the reserves and quality of the existing reserve talents, but also affects its long-term and lasting development. As far as China's current situation is concerned, the total number of competitive reserve talents is seriously insufficient, especially the lack of juvenile talent reserves. The development of tennis is related to the regional 
economic development and people's disposable income. In the middle and western part of economically backward cities, low economic level seriously restricts the development of this sport. At the same time, tennis training bases and venues for teenagers in China are nothing like enough. In addition, training system of tennis competitive personnel has not been sound, resulting in the lack of systematic and professional training of young reserve members.

Similarly, if our country wants to occupy a place in the international sports field for a long time, it is a must to stress the cultivation and selection of reserve talents. Excellent reserve athletes also are able to guarantee the country to achieve outstanding results. In recent years, although China's competitive tennis has made little progress in the international sports arena, there is still a big gap with the top level. Besides, the overall strength is not ideal, mainly reflected in the international low ranking of men's tennis competition.

With the diversification of China's economic development and the internationalization of competitive sports, tennis sports, represented by the characteristics of professionalization and marketization, make the ranking and honor of athletes' sports directly link with the interests of athletes and coaches. Athletes in the lure of high bonuses and fierce competition in the environment, are full of enthusiasm for training and competition, while coaches are more serious about training and competition. In order to get better results in the competition, all training arrangements of athletes are discussed by coaches and athletes together and formulated according to athletes' training level and actual situation, which is more suitable for athletes' own training intensity and rhythm with the feature of independence and particularity. However, in China, athletes' training and competition are all determined without their own participation. On the one hand, it results in athletes' dependence, laziness and lack of discipline in training because they bear less pressure. On the other hand, coaches have low enthusiasm for training, and offer inadequate professional guidance for training, which leads to a lower level of training.

The level of coaches directly affects the quality of excellent athletes. As far as the quantity and quality of coaches' reserves are concerned, on the one hand, the number of coaches is seriously insufficient, which seriously affects the cultivation of outstanding tennis reserve talents in China. On the other hand, their comprehensive quality is too low to give sufficient guidance to athletes. Existing coaches lack a systematic study and cognition of tennis competition, learning of tennis competitive skills and tactics as well as the discussion on the playing methods and tactics of top tennis players in the international tennis arena. Therefore, they are incapable of giving professional guidance. All these factors restrict the development level of tennis sports in China.

In today's international tennis world, each player's playing method has its own merits, so coaches' training tactics should also be constantly changing. In recent years, tennis tactics in our country have been improved in training, gradually improving quality of training. However, due to the low comprehensive quality of tennis coaches in China, the system of tennis competitions cultivation and training talents has not yet been improved, without an understanding of playing methods and techniques of top tennis players in the world as well as the analysis of opponents' tactics, which leads to coaches' lack of clear tactical formulation in the training process. Therefore, tennis skills and playing methods are too old-fashioned without the analysis of advantages and disadvantages of opponents and other issues, leading to the overall low level and ranking of China's tennis competitions. In the modern training mode of tennis talent, technical training and psychological training have been paid more and more attention. Meanwhile, improvement of professional ability has become the core content of improving competitive results.

\section{Development Strategies of Competitive Tennis in China}

In order to improve the level of tennis competitions in China as a whole, we must start with the selection and training of coaches. Only coaches with high level, strict standards and high requirements can train the same excellent tennis players. Therefore, we are advised to strengthen the establishment of training system for coaches and adjust different tactical countermeasures according to the training differences of different players and opponents. In the form of training, we should carry out a variety of teaching modes, through coaches' further study and other methods, 
fundamentally improve their professional level. Similarly, it is necessary to improve the training system of athletes. Training time, intensity, work and rest of athletes should be rationally arranged. In addition, it is vital to technically improve the quality of our athletes' service reception, enhance their technical weakness of backhand ball, enhance players' offensive and defensive ability to change, adjust their competition rhythm to grasp opportune ball and enhance the cultivation of athletes' ability to change and strain.

Modernized and internationalized competition environment also put forward higher requirements for coaches' teaching, requiring them to formulate a suitable training system for athletes according to their own conditions. It is necessary to strengthen the physical training of athletes, because their physical quality is the basis and guarantee for normal play of training and competition level. On the basis of ensuring athlete's physical fitness, we must increase the intensity of training to match the intensity of the event. Tennis matches generally last a long time, and a race may take several days to end, which is also a huge test for athletes, so this requires athletes, in the usual basic training, to be able to maintain a state of extreme tension for a long time. At the same time, coaches are proposed to also pay attention to the training of enhancing the coordination and explosive force of athletes' bodies, since good coordination is particularly important in the competition. Every swing and rotation action in the competition requires the cooperation of every muscle of the whole body. Explosive power is the process in which an athlete gathers all the power on the racket in a matter of seconds and bounces the ball back to the opponent. The power determines the speed and angle of rotation of the ball. A strong blow will also create strong psychological pressure and psychological burden on your opponent. In terms of psychological construction, it is a necessity to strengthen the construction of athletes' psychological quality, further improve their ability to resist pressure, and enhance their own control over the competition. In the basic training stage, athletes' physical training and coordinated explosive training are mainly to strengthen their physical fitness, so that they can maintain competitive state for a long time in the competition. In the improvement stage, technical improvement of players is targeted, including the training of their skills of serving and receiving. During competition, according to individual differences of professional athletes, scientific arrangement of training rhythm should be strengthened, so that training rhythm can sufficiently adapt to the normal behavior of athletes. In training, we are required to strengthen the training for the weaknesses, and seek to improve the overall strength.

We should vigorously advocate the scientific introduction of international tennis competition system, establish a set of competition system that can adapt to the actual training of players at all levels, increase competition opportunities of reserve talents, and strive to improve the quality and efficiency of competition. A good competition system plays an important role in cultivating athletes' sense of fair competition and improving their understanding of competition. According to their own characteristics of playing methods, athletes develop their own tactical strategies, improve their offensive and defensive conversion ability and rhythm transformation ability, as far as possible to reduce tactical loopholes. In training and competition, it can ensure that athletes can give full play to their own strength to reduce mistakes.

Taking full account of our tennis training system, we can employ high-level foreign teachers to improve the overall teaching level of coaches to integrate our tennis with the international competition system, so that more outstanding players from young people are willing to gradually step to the professional arena. As far as athletes are concerned, they are proposed to deepen their understanding of competitive competitions, enhance their sense of national honor and their own sense of honor, and build up their self-confidence and improve their self-discipline, so as to complete each match with the fullest enthusiasm and the most serious attitude.

In order to vigorously promote the national level of competitive tennis, it is necessary to strengthen the improvement of supporting infrastructure, through the construction of more tennis courts and purchasing of more tennis products and so on. In addition, we can also support colleges and universities to set up more tennis courses and other ways to improve people's awareness as well as enthusiasm for tennis sports, which requires more co-operation in many aspects. Nowadays, it is quite vital to speed up the construction of tennis courts and equipment, create a better teaching 
environment for our coaches and athletes, and contribute to the construction of the motherland's tennis teaching construction,

\section{Conclusion}

In a word, it is necessary to establish a set of reasonable training and management mechanism for athletes, keep them in a good state all the time and maintain a high level of competition as a whole, strengthen the scientific training of athletes' physical fitness, sports technology, tactics and psychology, enhance the construction of coaches, and constantly reduce the gap between our country and international level.

\section{References}

[1] Xu Chengjian, Shaanwei, Zou Chao. Analysis of the Distribution of Asian Professional Tennis Strength [J]. Anhui Sports Science and Technology, 2017,38 (06): 55-58.

[2] Su Xin, Zeng Qiang, Liu Xudong. Analysis of the Transfer Characteristics of World Tennis Competitive Advantage [J]. Journal of Harbin Institute of Physical Education, 2017, 35 (06): 84-90.

[3] Diao Kai, Zhang Jian. Research on the Training Mode and Professional Development of Tennis Competitive Sports Talents in China [J]. Journal of Nanjing Institute of Physical Education (Natural Science Edition), 2017,16 (05): 69-72.

[4] Zhang Can. Probe into the Problems and Countermeasures of Tennis Talents Training in China [J]. Journal of Nanjing Institute of Physical Education (Natural Science Edition), 2017,16 (04): 68-72.

[5] Wu Qiang. Generation and Development Trend of Chinese Competitive Tennis' "Sole” Mode [J]. Journal of Guangzhou Institute of Physical Education, 2017,37(04): 56-60.

[6] Ho Jieming. Research on the Core Competence of Regional Competitive Advantage of World Tennis [J]. Liaoning Sports Science and Technology, 2017,39 (01): 78-81. 